\title{
FUSION OF HIGH RESOLUTION REMOTE SENSING IMAGES AND TERRESTRIAL LASER SCANNING FOR IMPROVED BIOMASS ESTIMATION OF MAIZE
}

\author{
C. Hütt ${ }^{\mathrm{a}, *}$, H. Schiedung ${ }^{\mathrm{b}}$, N. Tilly ${ }^{\mathrm{a}}$, G. Bareth ${ }^{\mathrm{a}}$ \\ a Institute of Geography (GIS \& Remote Sensing Group), University of Cologne, 50923 Cologne, Germany - \\ (christoph.huett, nora.tilly, g.bareth)@uni-koeln.de \\ ${ }^{\mathrm{b}}$ Institute of Crop Science and Resource Conservation, University of Bonn, 53121 Bonn, Germany \\ henning.schiedung@uni-bonn.de
}

Commission VII, WG VII/5

KEY WORDS: Agriculture, Crop, Change Detection, TLS, Fusion, Multispectral, High resolution, Monitoring,

\begin{abstract}
:
In this study, images from the satellite system WorldView-2 in combination with terrestrial laser scanning (TLS) over a maize field in Germany are investigated. Simultaneously to the measurements a biomass field campaigns was carried out. From the point clouds of the terrestrial laser scanning campaigns crop surface models (CSM) from each scanning date were calculate to model plant growth over time. These results were resampled to match the spatial resolution of the WorldView-2 images, which had to orthorectified using a high resolution digital elevation model and atmosphere corrected using the ATCOR Software package. A high direct correlation of the NDVI calculated from the WorldView-2 sensor and the dry biomass was found in the beginning of June. At the same date, the heights from laser scanning can also explain a certain amount of the biomass variation $\left(r^{2}=0.6\right)$. By combining the NDVI from WorldView-2 and the height from the laser scanner with a linear model, the $\mathrm{R}^{2}$ reaches higher values of 0.86 . To further understand the relationship between CSM derived crop heights and reflection indices, a comparison on a pixel basis was performed. Interestingly, the correlation of the NDVI and the crop height is rather low at the beginning of June $\left(\mathrm{r}^{2}=0,4, \mathrm{n}=1857\right)$ and increases significantly $\left(\mathrm{R}^{2}=0,79, \mathrm{~N}=1857\right)$ at a later stage.
\end{abstract}

\footnotetext{
* Corresponding author: christoph.huett@uni-koeln.de
} 


\section{INTRODUCTION}

Sustainable modern agriculture practises have to guarantee food security for the increasing population of the world, minimize the difference of potential and actual yield, provide biomass for renewable energy production and optimize the input of fertilizers and pesticides while minimizing environmental impacts (Tilman et al. 2011, Gebbers et al. 2010). The only way to achieve those ambitious goals is the use of precision agriculture (Oliver 2013). But to apply this, measurements of plant parameters and its variability are needed with high temporal and spatial resolution over the area under investigation. Remote Sensing is the technology to provide exactly this information (Mulla 2013). In this study the reflection values from the optical satellite WorldView-2 and plant height monitored with Terrestrial Laser Scanning (TLS) are evaluated and combined to estimate the biomass of a maize field. Biomass is a very important parameter. It is the main input factor for the calculation of the Nitrogen Nutrion Index (NNI). With this parameter the manager of the field can use precision agriculture techniques to apply the exact amount of fertilizer (Lemaire et al. 2008). Wrong amounts of fertilizer are related to some very important issues such as climate change through $\mathrm{N} 2 \mathrm{O}$ release (Davidson et al. 2000) and water pollution through nitrate (Walton 1951).

\section{METHODS}

\subsection{Remote sensing of biomass}

Reflectances of different wavelengths of the electromagnetic spectrum are used to make estimations of plant parameters. Mainly the difference of red light absorbed by the chlorophyll and the reflected energy in the infrared domain can be directly linked to the amount of photosynthesis (Gates et al. 1965). Within the resolution cell of imaging sensors mounted on different platforms the Normalized Differenced Vegetation Index (NDVI) is used to use reflection for the approximation of the amount of photosynthesis. This amount of photosynthesis determines the biomass that is accumulated in the plant which leads to the yield. This approach has been well researched in the last decades and is applied on scales reaching from fields to regions (Moulin et al 1998). Progress of sensor technology has led to To use satellite remote sensing to monitor the scale underneath, the variations within a field or intra field variability is researched just after very high resolution sensors became available in the early 2000 s (e.g. Colombo et al 2003).

One aspect that is ignored when using only reflection values to estimate crop biomass is the $3^{\text {rd }}$ dimension. Imaging systems usually only scan the top canopy of vegetation. To include plant height and structure related parameters in the calculation of biomass could on the one hand reduce the uncertainty of the measurement and on the other hand overcome limitations of the approach such as saturation of vegetation indices from reflection measurements with higher biomass and uncertainty in the measurement of the growth stages of agricultural crops. for about 170-190 days. Due to the position in the Lee-Side of the Eifel mountain range the precipitation is a bit lower than typically observed in nearby regions. It ranges from 500 to $600 \mathrm{~mm} /$ year. This temperate climate combined with the fertile soils provides good conditions for the intense agricultural production of the region; the main crops are maize, wheat, barley, sugar beet and potatoes. The terrain is virtually flat with slopes ranging from 0 to $3^{\circ}$. The mean elevation is about $100 \mathrm{~m}$ above sea level.
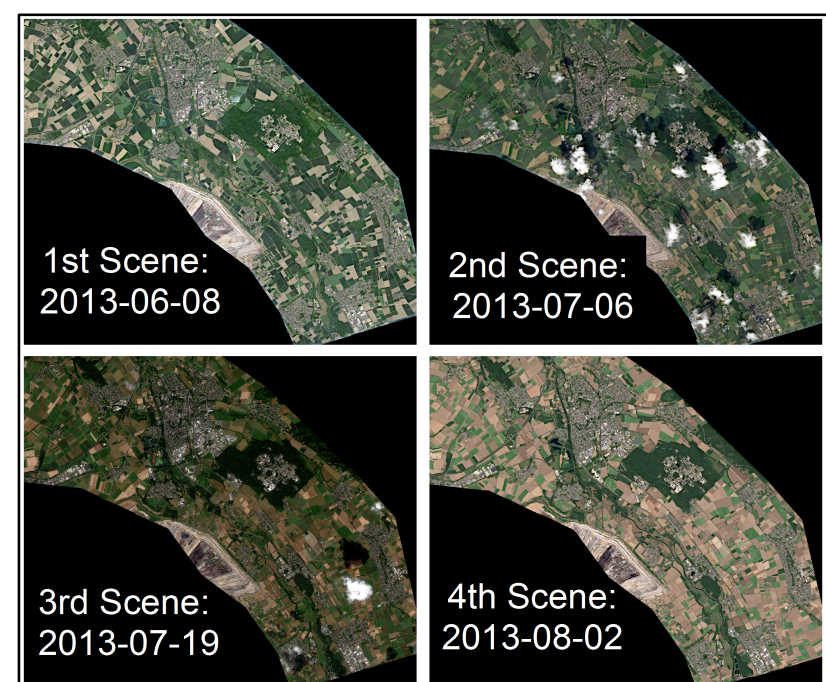

A

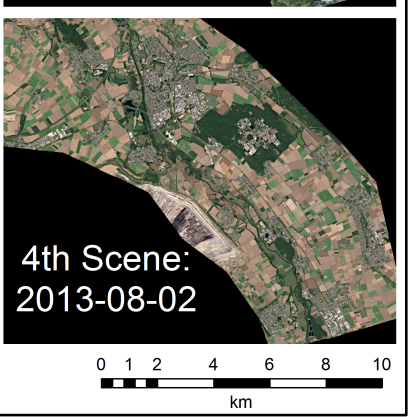

Figure 1. Overview of the four acquired WorldView-2 Scenes

The maize field is situated at N 50 $52^{\prime} 5^{\prime \prime}, \mathrm{E} 6^{\circ} 27^{\prime} 11^{\prime \prime}$ and has a spatial extent of about $60 \mathrm{~m}$ by $160 \mathrm{~m}$ and was chosen because of the heterogeneous soil conditions and thus an expected infield variability of the plant biomass. Figure 3 and 4 show the field from different perspectives on different dates. Figure 3 gives an overview of how the field looks like on the four WorldView-2 images.

The satellite WorldView-2 is an optical satellite that acquires images with 8 Bands in the visible and infrared domain of the electromagnetic spectrum with a spatial resolution of $2 \mathrm{~m}$ and a panchromatic band with $0.5 \mathrm{~m}$ resolution (Updike and Comp, 2010). Acquisitions were planned in the time frame where the most increase of biomass and plant height was anticipated. The actual image acquisitions took place on June $8^{\text {th }}$, July $7^{\text {th }}$, July $23^{\text {rd }}$ and August $7^{\text {th, }}$ Fig 1 gives an overview of the Area that was covered. It consists of a strip of about $5 \mathrm{~km}$ width and approximately $15 \mathrm{~km}$ in length; the area is about $100 \mathrm{~km}^{2}$.

\subsection{Study Site and Data acquisition}

All measurements of this study were carried out in the growing season of 2013 on a maize field situated near the village Selhausen-Niederzier. The next bigger cities are Düren $(\sim 10 \mathrm{~km})$, Aachen $(\sim 30 \mathrm{~km})$ and Cologne $(\sim 40 \mathrm{~km})$. Mean Temperature varies from $9-11^{\circ} \mathrm{C}$ and the vegetation period last 


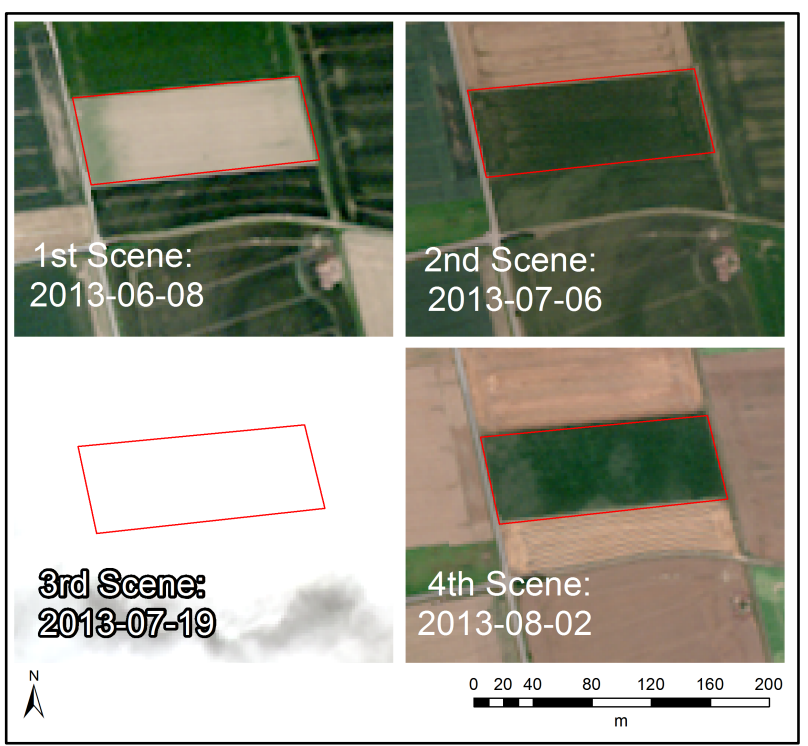

Figure 2. Overview of the area of interest on the four satellite scenes. Note the cloud cover on the $3^{\text {rd }}$ scene which made any analysis impossible.

Terrestrial laser scanning (TLS) measurements were carried out on 6 dates between May and September 2013. On each date the maize field was scanned with the TLS system Riegl LMS-Z420i (Riegl GmbH, 2010) mounted on a cherry picker and thereby reaching a height of about 8 meters. Four positions were chosen around the field corners to cover the whole field and minimize shadowing effects. For this study only the 2 datasets acquired on July $3^{\text {rd }}$ and July $31^{\text {st }}$ were used as they can be related to the $2^{\text {nd }}$ and $4^{\text {th }}$ satellite acquisition. Those were the only acquisitions where meaningful reflection values of the maize field could be extracted. A more detailed description of the season long TLS measurements can be found in Tilly et al. (2014).

Corresponding to the TLS campaigns biomass was destructively taken. At 12 sample points distributed in the field, five plants were taken and their aboveground biomass was dried and and measured. The position of the points was measured using the highly accurate RTK-DGPS system Topcon HiPer Pro (Topcon Positioning Systems Inc., 2006). Again in this study only the biomass samplings at the time of the $2^{\text {nd }}$ and $4^{\text {th }}$ World-View2 acquisition were useful. Unfortunately the processing of biomass was difficult for the $4^{\text {th }}$ date due to technical problems while drying the biomass. Some plants were not completely dry before weighing therefore the biomass from this date was not used in this study.

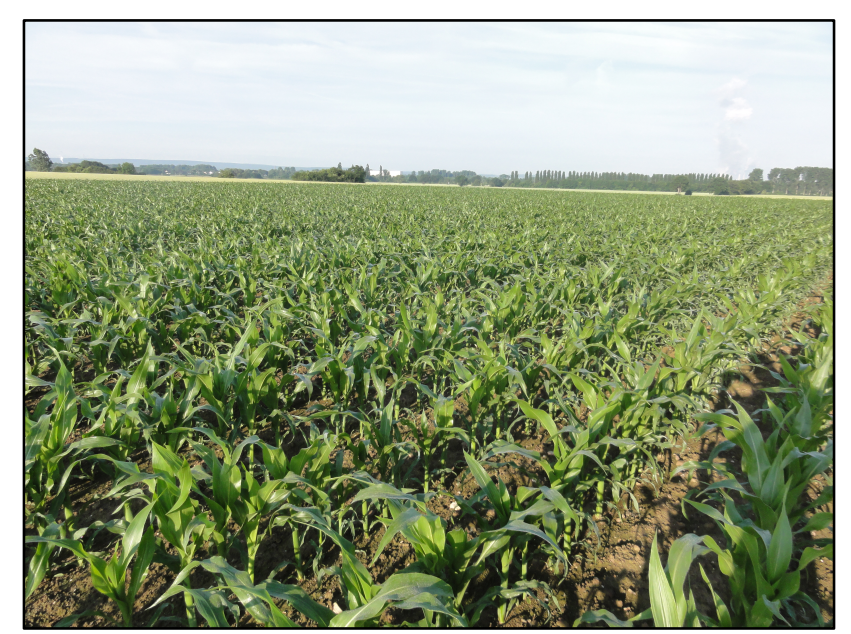

Figure 3. Southwest looking photo of the maize field on July $2^{\text {nd }}$, shortly before the $2^{\text {nd }}$ WorldView-2 acquisition

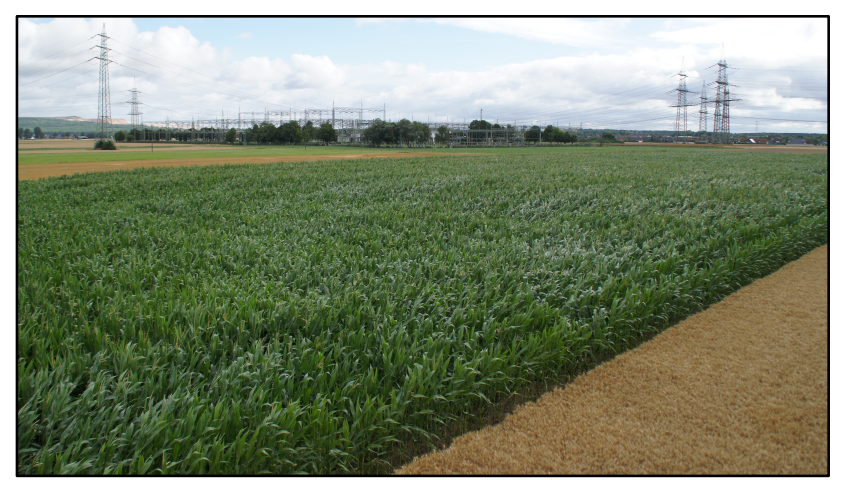

Figure 4. Northeast looking photo of the maize field on July $31^{\text {st }}$, just before the $4^{\text {th }}$ WorldView-2 acquisition.

\subsection{Satellite data processing}

A digital elevation model provided by the "Landesvermessungsamt NRW" with a $1 \mathrm{~m}$ spatial resolution was used to correct the topography related distortions of the images. For this orthorectification the only additional information that was needed was the Rational Polynomial Coefficients (RPC) with sensor information at the time of the acquisition that are provided with the satellite images. Ground Control Points were not needed. However, to test the spatial accuracy of the outcome a comparison of the orthorectified panchromatic image to digital orthophotos (DOP) from the "Landesvermessungsamt NRW" in $40 \mathrm{~cm}$ resolution was performed. The absolute positional accuracy of these images is stated to be less than $6 \mathrm{dm}$ (Geobasis NRW, 2014). To evaluate the absolute accuracy of the orthorectified images 5 check points mainly in urban areas distributed over the image area were used. The panchromatic images with a spatial resolution of $50 \mathrm{~cm}$ positioned at the same location as the multispectral 8 Band image was used to evaluate the accuracy of the multispectral image at a sub pixel level of the multispectral image (Fig 5).

The ATCOR2 Software Package from Geosystems was used to correct the signal that was received at the satellite for the atmospheric distortion that exists in all optical satellite imagery. The algorithm was supplied with positions of the satellite and 
the sun at the time of image acquisition which can be found in the metadata file delivered with images. The visibility parameter acquired by the Deutscher Wetterdienst (DWD) at the nearby weather observation station Düren were included to approximate the condition of the atmosphere at the time of image acquisition. As the open pit coal mining in this area and the surrounding cities are responsible for an increased amount of fine particular matter in the atmosphere the approximation parameter for the atmosphere was set to rural. The resultant reflectance values are the basis of the calculation of the NDVI from the bands of the WorldView-2 sensor. Mutanga et al. (2012) state that the NDVI calculated from the red edge (band 6) and NIR (band 8) improve the prediction accuracy of biomass and was therefore used in this study.

\subsection{Statistical Analysis}

The TLS-derived data sets are used to create Crop Surface Models (CSMs), introduced by Hoffmeister et al. (2010) for plant growth monitoring. One CSM represents the crop surface of the whole field in a high resolution of $1 \mathrm{~cm}$. As described in Tilly et al (2014a), CSMs can be used to calculate plant height pixel-wise. For the combined analysis of the data sets, the high resolution CSMs had to be downsampled to match the comparatively coarse resolution of $2 \mathrm{~m}$ of the multispectral WorldView-2 satellite. This was done using the mean crop height from the CSM per pixel area of the satellite image.

For the extraction of all the values a regular point grid was created with the distance between points as long as the raster resolution. The ArcGIS-tool "extract multiple values at points" can then be used to extract the different reflection values of the 8 bands from different acquisitions of the WorldView-2 Satellite and the downsampled CSMs. Data from the biomass campaign was added to this complete dataset at those 12 points where ground measurements were made. The statistical analyses were done using the R software package (R Development Core Team, 2014) and included computation of the NDVI values and linear regression analysis. Correlation and regression analyses were carried out to investigate the accuracy of the results and examine the usability of WorldView-2 in combination with plant height as predictor for biomass of maize.

\section{RESULTS}

\subsection{Positional Accuracy of the orthorectified WorldView-2} images.

The CSMs from the laserscanning were acquired with a very high positional accuracy. The relative accuracy is less than $1 \mathrm{~cm}$ whereas the absolute accuracy depends on the used DGPS which in this case is less than 1 meter. A combined analysis with the optical satellite images only makes sense if their absolute positional accuracy also reaches high precision. Fig 1 shows one of 5 checkpoints where the positional accuracy of the satellite images was tested. Table 1 shows the results for all the points. The absolute positional error of the images was never higher than two multispectral pixels and on average a little bit larger than one multispectral pixel. Therefore a combined analysis with the CSM derived plant heights is possible. The spatial combination in the GIS revealed spatial accordance of the datasets.

\begin{tabular}{|c|c|c|c|c|}
\hline \multirow[t]{2}{*}{ CheckPoint } & \multicolumn{4}{|c|}{$\begin{array}{l}\text { absolute location error of orthorectified } \\
\text { WV-2 to DOP }[\mathrm{m}]\end{array}$} \\
\hline & 08-06 & $07-06$ & 07-19 & 08-02 \\
\hline 1 & 1,0 & 3,5 & 1,2 & 3,7 \\
\hline 2 & 2,2 & 3,1 & 0,4 & 2,6 \\
\hline 3 & 3,6 & 3,6 & 0,8 & 2,5 \\
\hline 4 & 3,4 & 3,2 & 1,3 & 3,8 \\
\hline 5 & 1,6 & 3,5 & 3,1 & 2,2 \\
\hline Mean & 1,36 & 2,96 & 3,38 & 2,36 \\
\hline Max & 3,1 & 3,8 & 3,6 & 3,6 \\
\hline & & & $\begin{array}{l}\text { total } \\
\text { mean: } \\
\text { max: }\end{array}$ & $\begin{array}{r}2,52 \\
3,8\end{array}$ \\
\hline
\end{tabular}

Table 1. Absolute positional error of the WorldView-2 images.

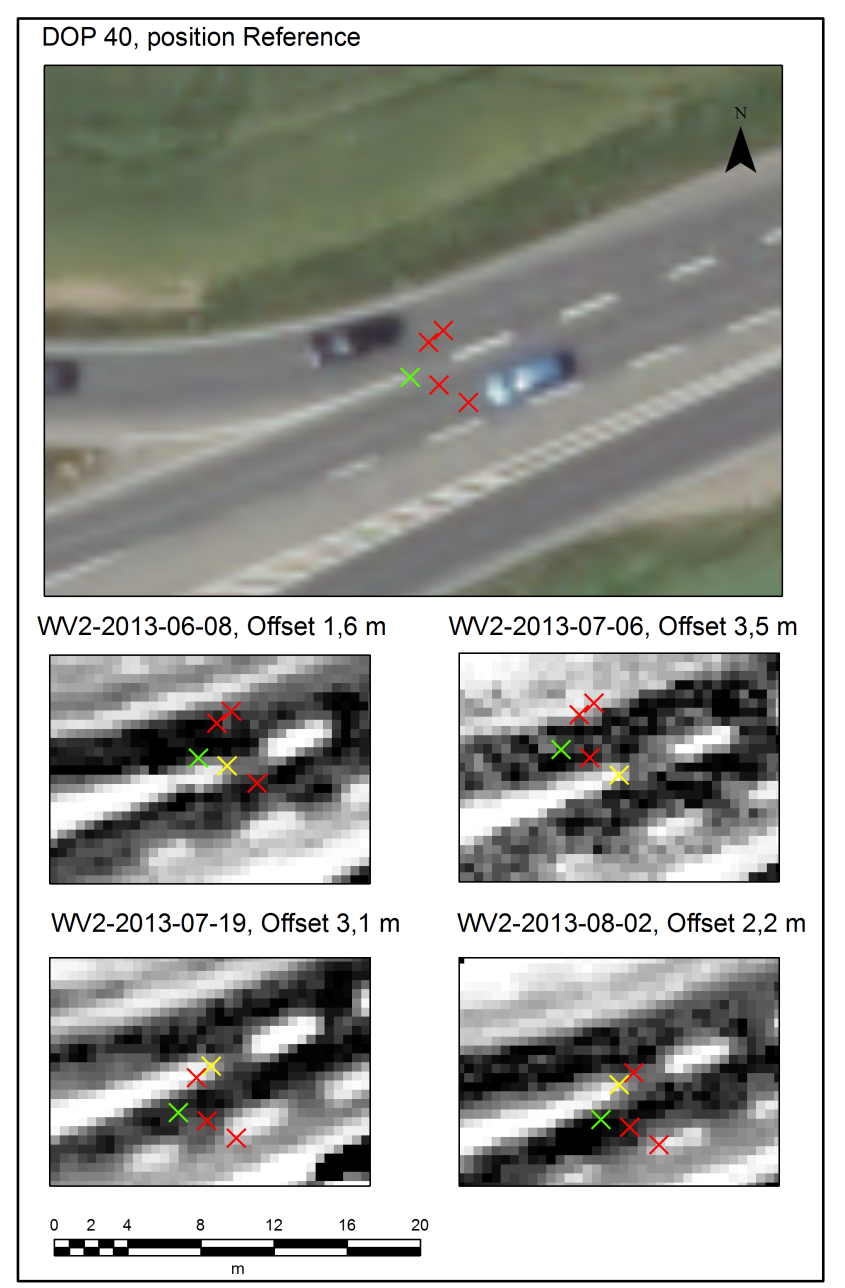

Figure 5. Accuracy checkpoint 5 and its position in the 4 satellite scenes. The total offset distance is always less than 2 multispectral pixels. 


\subsection{Statistical analysis}

As the positional accuracy of the WorldView-2 images is sufficient for a combined analysis with the CSM derived plant height, correlation analysis were performed. The results can be divided into two parts:

I: Correlation of all measurements of the field. Analysis of the CSM derived plant heights and the reflection from WorldView2 at the $2^{\text {nd }}$ satellite image (WV-2: 2013-07-06, TLS: 2013-0703 ) and about 1 month later at the $4^{\text {th }}$ image (WV-2: 2013-0802, TLS: 2013-07-31)

II: Biomass estimation with a combination of the data from the $2^{\text {nd }}$ satellite image (2013-07-06) and the CSM derived plant height from the 2013-07-03.

The first analysis from beginning of July where the maize plants are about $75 \mathrm{~cm}$ high reveals that the CSM plant height and the NDVI values are somehow related but not highly correlated $\left(\mathrm{R}^{2}=0.4\right)$. This indicates that the measurements contain independent information (Fig. 6). This changes at the end of July, where the plant height and NDVI have both increased a lot (Fig. 7). The maize plants have almost tripled in size and the NDVI values are a little less than twice as high. Here the $\mathrm{R}^{2}$ increases to 0.79 which is a indicator for redundant information of the 2 measurements but also a proof that the proposed fusion is possible.

The second part made use of the biomass sampling at the 12 points ( 5 plants for each point). For the beginning of July with the linear regression analysis with CSM derived plant height and NDVI from WorldView-2 as estimator for the biomass the following formula was established:

Formula 1: Dry Biomass $=$ CSM derived plant height $* 7.17+$ WorldView2 NDVI (Bands 8+6) * 131.697 - 26.053
Figure 10 shows the predicted biomass values from this formula plotted against the real measured values. The high $\mathrm{R}^{2}$ of 0.86 shows the high correlation of the combination of the measurements. It has to be noted that this formula is valid for on date and one field only.

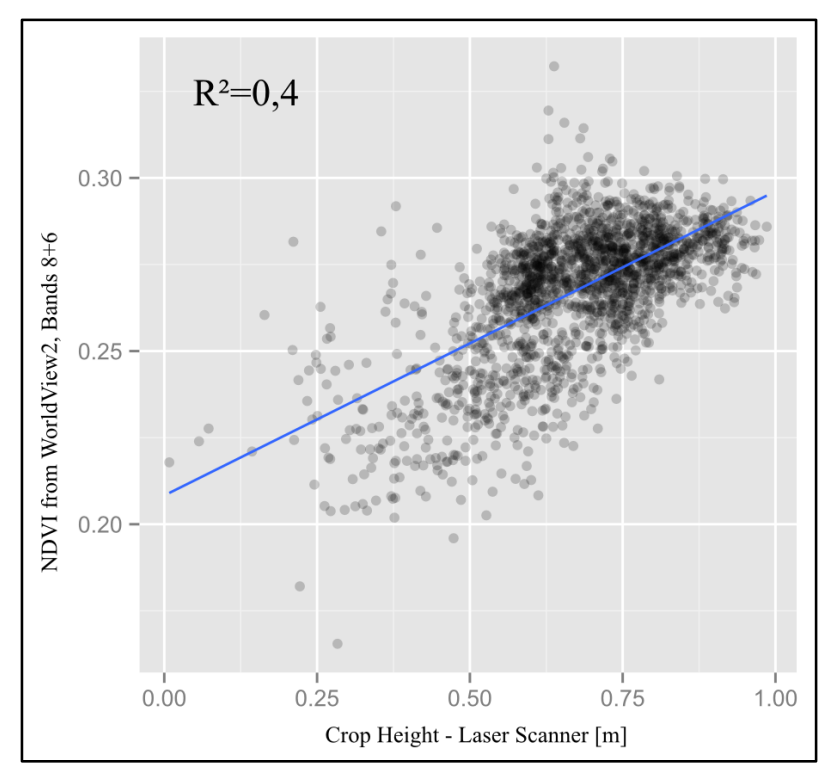

Figure 6. Correlation of NDVI from WorldView-2 (July $\left.7^{\text {th }}\right)$ and CSM-derived plant height from July, $3^{\text {rd }}$ $(\mathrm{N}=1857)$

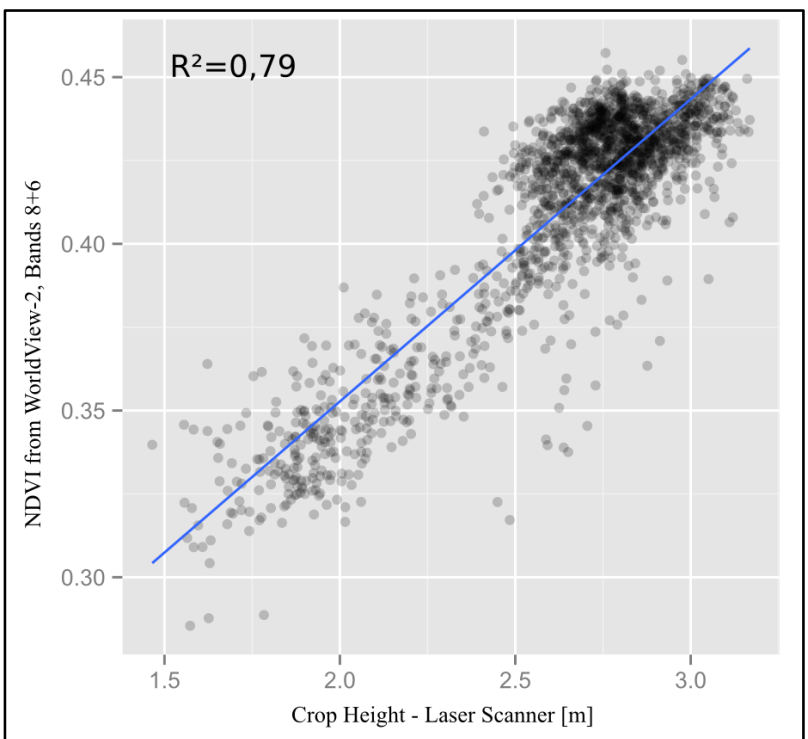

Figure 7. Correlation of NDVI from WorldView-2 (August $7^{\text {th }}$ ) and CSM-derived plant height from July 31 th $(\mathrm{N}=1857)$ 


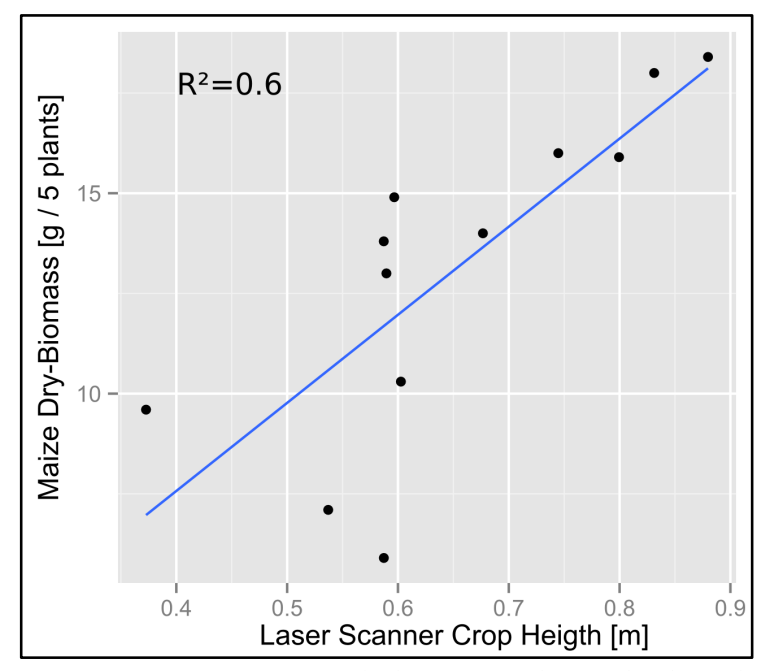

Figure 8. Regression of the CSM-derived plant height from July $3^{\text {rd }}$ and dry biomass. $(\mathrm{N}=12)$

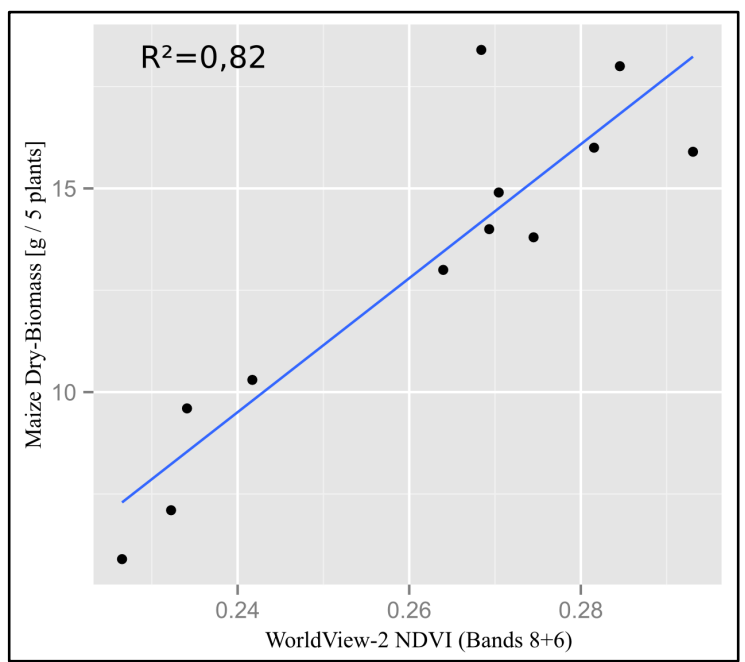

Figure 9. Regression of the NDVI (Bands 8+6) from $2^{\text {nd }}$ WorldView-2 acquisition from the $6^{\text {th }}$ July and the dry biomass taken on $3^{\text {rd }}$ July $(\mathrm{N}=12)$.

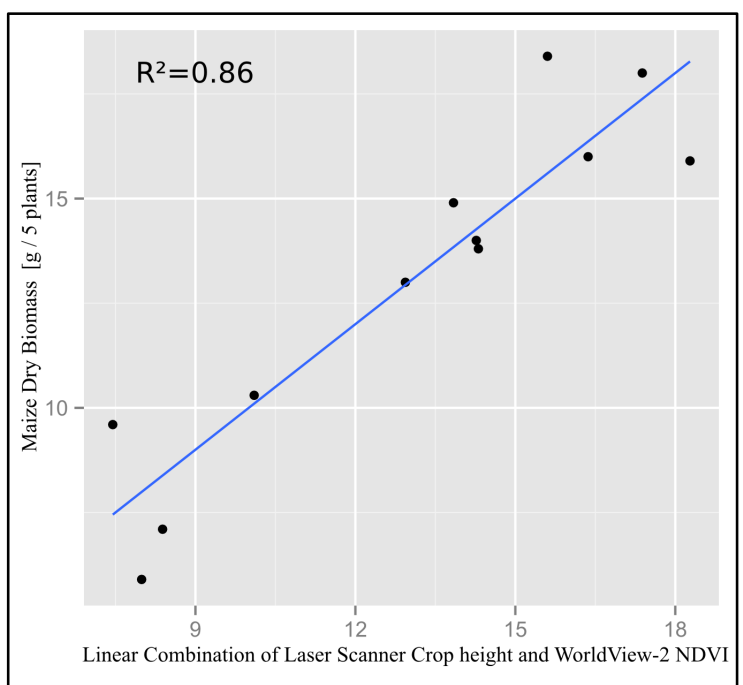

Fig. 10: Regression of the linear (best Fit) combination of CSM-derived plant height and NDVI (Bands 8+6) from WorldView-2 with the dry biomass.

\subsection{Spatial analysis}

Based on the findings from the statistical analysis, Formula 1 was used to calculate a biomass map from the linear combination of WorldView-2 NDVI and CSM derived plant height of the whole maize field. Fig. 11 shows the biomass distribution as sensed by the combination of the two sensors. In the western part the values are lower due to delayed plant development. The red line from north to south in the eastern part of the field results from drilling practices: The drilling machine had to drill in opposite directions in the end parts of the field. In those small lines with higher biomass predictions there there are twice as many plants due to overlapping of the drilling rows. Plant density was anticipated to be homogeneous over the field and was therefore not taken into account in this approach.

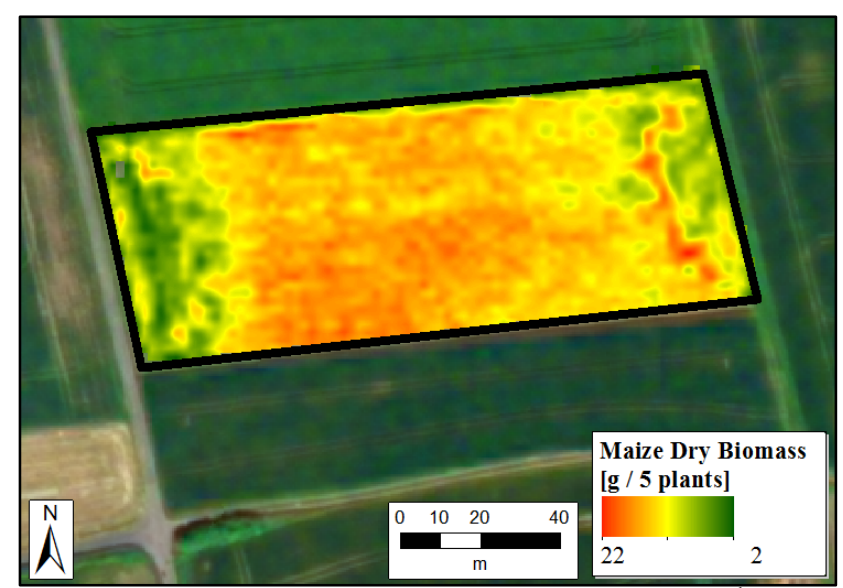

Figure 11. Final dry biomass Map for the $2^{\text {nd }}$ date (07.07.2013), calculated from WorldView-2 NDVI and CSM derived plant height using formula 1. Background: Pansharpened WorldView-2 image from $8^{\text {th }}$ June.

\section{DISCUSSION}

Anticipated results were that TLS is able to monitor plant growth and its variability over the period where plant growth is dominant as shown by Hoffmeister et al. (2013) and Tilly (2014a). Some limitations were expected if it comes to computation of the field variability at single dates. This in contrast was supposed to be the advantage of optical very high resolution imagery such as from the WorldView-2 for example shown by Colombo et al. (2003).

The conducted field experiment revealed the difficulties of field experiments. Only two out of four satellite scenes could be linked to ground measurements. The biomass sampling could only be related to one of the images. For this event, however, the synergetic use of TLS and reflectance indices from optical sensors the improvement of the estimation of biomass for the biomass of the maize field was demonstrated. With the help of TLS, the third dimension in the calculation of biomass could be added and the precision of the calculation was increased. The high values of the $\mathrm{R}^{2}$ of 0.86 has to treated cautiously as the established formula is only valid for a single field for one date. The biomass used to establish the formula was also used to calculate the $\mathrm{R}^{2}$. An independent biomass sampling dataset would be needed to properly asses the accuracy of the proposed method. 
However a spatial representation of the formula revealed patterns of intra-field biomass variability that can be related to the status of the field and could be the basis for further investigations. At a later stage, the similarity of the measurements of the two sensors was shown. But if two measurements are highly correlated it seems not meaningful to combine them as proposed. Other values from TLS could be extracted. Höfle (2014) showed how to extract individual maize plants from TLS. This approach could help to refine the proposed method as plant density was expected to be homogeneous all over the field and therefore not taken into account. Also it has to be noted that the spatial resolution of the TLS was degraded a lot to match the $2 \mathrm{~m}$ pixel size of the WorldView-2 sensor. A different approach could include a upscaling of the WorldView-2 image to make use of the spatially far more precise TLS measurements.

Also it has to be noted that TLS measurements are very labor intense and can only be made for single selected fields. The main advantage of satellite imagery is transferability to larger areas with hardly any additional effort. On the other hand, consideration of the crop calendar has to be taken into account when monitoring crops with satellite images and clouds can make analysis impossible. A complete season long monitoring with optical very high resolution images seems only possible when the number of acquisitions is dramatically increased as for example shown by Claverie et al. (2012), who used 95 FORMOSAT-2 images at 8 meter resolution to monitor maize on a field level and stated the research of intra field variability as a future focus.

\section{CONCLUSION AND OUTLOOK}

In summary, the good potential of the WorldView-2 Sensor to monitor intra field biomass variation of a maize field was demonstrated for a single date. Height from TLS was included by combining crop surface models into the estimation of biomass and the measurement could be further refined. At a later stage the synergetic effects of the fusion have to be doubted as high correlation of the two sensors has been found. Limitations of optical satellite acquisitons due to cloud cover and problems in the processing of the biomass made it difficult to monitor the field for an extended period of time. More study is needed to understand the relation of plant height, reflectance and the accumulated biomass of maize.

The measurements are repeated in the growing season 2014 with refinements learned from this study. Future analysis include multiple acquisitions of other satellites to also extract crop height variations from a satellite platform for an extended area.

\section{REFERENCES}

Claverie , M., Demarez, V., Duchemin, B., Hagolle, O., Ducrot, D., Marais-Sicre, C., Dejoux, J.-F., Huc, M., Keravec, P., Béziat, P., Fieuzal, R., Ceschia, E. and Dedieu, G., 2012. Maize and sunflower biomass estimation in southwest France using high spatial and temporal resolution remote sensing data. Remote Sensing of Environment, 124, pp. 844-857. doi: 10.1016/j.rse.2012.04.005
Colombo R., Bellingeri, D., Fasolini, D., Marino, C.M. 2003. Retrieval of leaf area index in different vegetation types using high resolution satellite data. Remote Sensing of Environment, 86, pp.120-131, doi: 10.1016/S0034-4257(03)00094-4

Davidson, E. A., Keller, M.; Erickson, H. E., Verchot, L. V. and Veldkamp, E. 2000. Testing a conceptual model of soil emissions of nitrous and nitric oxides. BioScience, 50, pp. 667680 .

doi: $\quad$ 10.1641/0006-3568(2000)050[0667:TACMOS]2.0.CO;2

Gates, D. M., Keegan, H. J., Schleter, J. C., Weidner, V. R. 1965. Spectral properties of plants. Applied optics, 4(1), pp. 1120.

Gebbers, Robin, and Viacheslav I. Adamchuk., 2010. Precision agriculture and food security. Science, 327, pp 828-831.

Geobasis NRW 2014. Digitale Orthophotos. http://www.bezregkoeln.nrw.de/brk_internet/geobasis/luftbilderzeugnisse/digitale_ orthophotos/index.html

Hoffmeister, D., Bolten, A., Curdt, C., Waldhoff, G. and Bareth, G., 2010. High resolution Crop Surface Models (CSM) and Crop Volume Models (CVM) on field level by terrestrial laserscanning. Proc. SPIE, 7840, 78400E, 6 p. doi: $10.1117 / 12.872315$.

Hoffmeister, D., Waldhoff, G., Curdt, C., Tilly, N., Bendig, J. and Bareth, G., 2013. Spatial variability detection of crop height in a single field by terrestrial laser scanning. - In: Stafford, J.V. (Ed.), Precision agriculture '13, Proc. of the 9th European Conference on Precision Agriculture (JUL 07-11, 2013), Lleida, Spain. Wageningen Academic Publishers, pp. 267-274.

Höfle, B., 2014. Radiometric Correction of Terrestrial LiDAR Point Cloud Data for Individual Maize Plant Detection. IEEE Geoscience and Remote Sensing Letters, 5 p. doi: 10.1109/LGRS.2013.2247022.

Moulin, S., Bondeau, A., Delecolle, R. 1998. Combining agricultural crop models and satellite observations: From field to regional scales. International Journal of Remote Sensing 19, pp. 1021-1036, doi: 10.1080/014311698215586

Mulla, D.J., 2013. Twenty five years of remote sensing in precision agriculture: Key advances and remaining knowledge gaps. Biosystems Engineering, 114, pp. 358-371.

Mutanga, O., Adama, E., Cho, M.A., 2012. High density biomass estimation for wetland vegetation using WorldView-2. imagery and random forest regression algorithm. International Journal of Applied Earth Observation and Geoinformation, 18, pp. 399-406

Lemaire, G., Jeuffroy, M.H., Gastal F., 2008. Diagnosis tool for plant and crop $\mathrm{N}$ status in vegetative stage theory and practices for crop N management. European Journal of Agronomy, 28, pp. 614-624

Oliver, M., 2013. An overview of precision agriculture. In M. Oliver, T. Bishop, \& B. Marchant (Eds.), Precision Agriculture for Sustainability and Environmental Protection. USA.

Riegl LMS GmbH, 2010. Datasheet Riegl LMS-Z420i. http://www.riegl.com/uploads/tx_pxpriegldownloads/10_DataS heet_Z420i_03-05-2010.pdf(30.Jul. 2014) 
R Development Core Team, 2014. R: A Language and Environment for Statistical Computing. R Foundation for Statistical Computing, Vienna, Austria.

Tilly, N., Hoffmeister, D., Aasen, H., Brands, J. and Bareth, G., 2014a. Multi-temporal Crop Surface Models derived from terrestrial laser scanning for accurate plant height measurement and biomass estimation of barley. Kölner Geographische Arbeiten, 94, 83-91. doi:10.5880/TR32DB.KGA94.12

Tilly, N., Hoffmeister, D., Schiedung, H., Hütt, C.,

Brands, J., Bareth, G. 2014. Terrestrial laser scanning for plant height measurement and biomass estimation of maize. The International Archives of the Photogrammetry, Remote Sensing and Spatial Information Sciences, Volume XL-7, 29 September - 2 October 2014, Istanbul, Turkey - in review.

Tilman, D., Balzer, C., Hill, J., Belfort, B. L. 2011. Global food demand and the sustainable intensification of agriculture. Proceedings of the National Academy of Sciences of the United States of America, 108. doi: 10.1073/pnas.1116437108

Topcon Positioning Systems, Inc. 2006. HiPer Pro Operator's Manual. http://www.top-survey.com/topsurvey/downloads/HiPerPro_om.pdf (30. Jul. 2014)

Walton, G., 1951. Survey of literature relating to infant methemoglobinemia due to nitrate-contaminated water. American Journal of Public Health and the Nations Health 41, pp. 986-996. 